Izumi, Volume 8 No 2, 2019

e-ISSN: 2502-3535 p-ISSN: 2338-249X

Tersedia online di http://ejournal.undip.ac.id/index.php/izumi

\title{
Kontrol Informal dan Formal Terhadap Yakuza di Jepang
}

\author{
Zaki Ainul Fadli*, Femiga Salsa Nabila \\ Universitas Diponegoro \\ *Email: zakiaf@live.undip.ac.id
}

\begin{abstract}
(Title: Informal and Formal Controls Against Yakuza in Japan) This research explores how far yakuza's development in Japan and to find social factors which affecting its change. The methods used are literary research. This paper discusses the implementation of formal and informal social control in Japanese society and its ties to yakuza. The fact that yakuza, as Japanese mafia, have been intervening its society for decades, is a strange phenomenon since Japan is known for its low crimes as portrayed on most of the media. The formal control section will be focused on the National Police Agency of Japan, while the informal control section will be focused on Japanese society, emphasizing on its culture. Both controls leave the door open for yakuza to establish power in society. This may lead to the conclusion that Japan's social control is relatively weak.
\end{abstract}

Keywords: Japanese society; yakuza; crime; social control

\begin{abstract}
Abstrak
Penelitian ini mengeksplorasi sejauh mana perkembangan yakuza di Jepang dan untuk menemukan faktor sosial yang mempengaruhi perubahannya. Metode yang digunakan adalah metode kualitatif. Makalah ini membahas penerapan kontrol sosial formal dan informal dalam masyarakat Jepang dan hubungannya dengan yakuza. Fakta bahwa yakuza, sebagai mafia Jepang, telah mengintervensi masyarakatnya selama beberapa dekade, adalah fenomena aneh karena Jepang dikenal karena kejahatannya yang rendah seperti yang digambarkan di sebagian besar media. Bagian kontrol formal akan difokuskan pada Badan Kepolisian Nasional Jepang, sedangkan bagian kontrol informal akan difokuskan pada masyarakat Jepang, dengan penekanan pada budayanya. Kedua kontrol membiarkan pintu terbuka bagi yakuza untuk membangun kekuatan dalam masyarakat. Simpulan dari tulisan ini menunjukkan bahwa kontrol sosial di Jepang relatif lemah
\end{abstract}

Kata Kunci: Masyarakat Jepang; yakuza; kejahatan; kontrol sosial

PENDAHULUAN

Jepang merupakan negara maju di Asia dengan tingkat kriminalitas rendah. Masyarakat dunia pada umumnya setuju dengan pernyataan ini, begitu pula dengan masyarakat Indonesia. Namun, sejatinya pandangan ini hanya berdasarkan pada standar kriminologi barat yang kurang sesuai 
Izumi, Volume 8 No 2, 2019

e-ISSN: 2502-3535 p-ISSN: 2338-249X

Tersedia online di http://ejournal.undip.ac.id/index.php/izumi

diterapkan dalam mempelajari kriminologi Asia, terutama Jepang, yang kompleks (Liu \& Miyazawa, 2018). Sehingga, dapat dikatakan bahwa dinamika aktivitas kejahatan di Jepang tidak serendah yang diduga orang-orang awam. Berbicara mengenai kriminalitas dan Jepang, sangat erat kaitannya dengan yakuza. Kaplan, dalam bukunya banyak menjelaskan bagaimana bisnis yakuza menginfiltrasi setiap sendi kehidupan masyarakat Jepang, serta betapa sulitnya melepaskan cengkeraman mereka sepenuhnya dari kehidupan sehari-hari.

Tulisan dan atau penelitian terdahulu mengenai Yakuza pernah dilakukan oleh beberapa orang. Penelitian Hill (2003) membahas perkembangan dalam kegiatan bisnis yakuza/ boryokudan (sindikat kejahatan terorganisir Jepang) setelah berakhirnya periode Showa pada tahun 1989 .

Kontrol sosial lazim dilakukan oleh masyarakat terhadap pihak yang mengancam keselamatan masyarakat, baik kontrol formal maupun informal. Terkadang kontrol formal lebih efektif dibandingkan informal. Akan tetapi tidak jarang pulang kontrol informal lebih efektif. Berdasarkan (Braithwaite, 1989; Johnson, 2003) dikatakan bahwa "hukuman pidana formal adalah senjata kontrol sosial yang tidak efektif" dan bahwa "komitmen budaya untuk mempermalukan pelaku kejahatan adalah kunci untuk mengendalikan semua jenis kejahatan ".

Melihat kontradiksi antara masyarakat Jepang yang kita kenal saat ini dengan realita eksistensi yakuza menarik perhatian penulis yang kemudian melatarbelakangi topik dari artikel ini. Penelitian ini menekankan pada bagaimana kontrol sosial berupa kontrol formal dan informal terhadap eksistensi Yakuza di Jepang. Hal ini dirasa cocok dengan model organisasi kriminal seperti yakuza karena akan melibatkan pembahasan mengenai otoritas penegak hukum dan budaya masyarakat di Jepang. Tujuan penelitian adalah untuk mengulas kontrol formal dan informal terhadap yakuza di Jepang.

\section{METODE}

Penelitian ini menggunakan dengan metode studi pustaka, yaitu pengumpulan data lewat sumber-sumber kepustakaan yang tersedia baik secara fisik maupun elektronik. Datadata yang dihimpun selanjutnya dianalisis dan dicari benang merahnya untuk mendapatkan kesimpulan.

\section{PEMBAHASAN}

\section{1) Yakuza}

Dalam permainan hanafuda, salah satu kombinasi terburuk adalah angka 8-9-3, bisa dibaca sebagai $y a-k u-s a$, merupakan asal nama yakuza yang dapat diartikan sebagai sesuatu yang tidak berguna bagi masyarakat. Yakuza lebih sering disebut sebagai bouryokudan oleh kepolisian Jepang dalam dokumen-dokumen resmi yang dapat diartikan sebagai 'sekelompok orang yang menggunakan kekerasan' (P. Hill, 2003).

Yakuza dapat diidentifikasi sebagai suatu bentuk kejahatan terorganisasi yang khas di Jepang (Albanese, 2016). Akarnya dapat ditelusuri dari ronin-ronin yang hidup pada zaman Edo, tepatnya berasal dari legenda machi yakko. Maka tidak heran apabila para yakuza merupakan penggemar cerita-cerita samurai, sehingga mereka mengimplementasikan sistem nilai bushido atau kode etik samurai dalam organisasinya (Kaplan, 2011, p. 17). Nilai bushido merupakan produk dari sistem shinokoso yang kental dengan feodalisme, maka dari itu melahirkan pola shuju kankei atau hubungan oyabun-kobun (atasan-bawahan) (Wibawarta, 2006). Dalam suatu organisasi yakuza, oyabun berperan sebagai mentor 
bagi kobun atau anak buahnya. Pola hubungan ini hampir dapat disamakan dengan peran senior-junior, namun lebih rumit.

Hubungan antara mentor dengan anak buah ini diikat dengan ritual inisiasi sakazuki, yaitu upacara bertukar cawan berisi sake yang menandakan ikatan persaudaraan antara calon anggota baru dengan seniornya di kelompok yang bersangkutan. Volume sake yang dituang disesuaikan dengan tingkat mereka, dimana oyabun mendapat cawan berisi sake lebih banyak dibandingkan dengan kobun-nya. Ritual inisiasi sakral semacam ini bukanlah hal yang jarang ditemukan karena juga dilakukan oleh beberapa organisasi kejahatan lainnya. Di Amerika Serikat misalnya, kelompok Cosa Nostra (gangster Amerika keturunan Italia yang berasal dari Sisilia) biasa menginisiasi anggota barunya melalui ritual pembakaran foto santo dan mengutarakan sumpah setianya kepada organisasi, yang berarti ia akan bernasib sama dengan foto yang dibakar apabila melanggar omerta atau code of silence (Raab, 2013). Sebagai tambahan, perlu diketahui tiga kelompok yakuza terbesar di Jepang, diantaranya adalah Yamaguchigumi di Kobe, Sumiyoshi-kai di Tokyo, dan Inagawa-kai di Tokyo. Masing-masing bisa memiliki cara kerja yang berbeda. Sebagai contoh, Yamaguchi-gumi memiliki struktur hierarki piramida, sedangkan struktur Sumiyoshi-kai lebih terdesentralisasi (Kaplan, 2011, p. 143).

Adapun istilah bakuto dan tekiya untuk membedakan kelompok yakuza yang berasal dari kalangan penjudi dan pedagang pada masa lalu. Hal ini dapat dijadikan gambaran mengenai tipikal bisnis apa saja yang dijalankan oleh kelompok-kelompok yakuza di masa mendatang. Laporan yang bersumber dari Keisatsu-chou menyatakan latar belakang yakuza Jepang sebagai berikut.

Tabel 1. Latar belakang anggota-anggota yakuza (Kaplan, 2011, p. 185).

\begin{tabular}{lllll}
\hline \multicolumn{1}{c}{ Pekerjaan } & \multicolumn{1}{c}{$\begin{array}{c}\text { Anggota } \\
\text { Penuh }\end{array}$} & $\begin{array}{c}\text { Anggota } \\
\text { Tambahan }\end{array}$ & Total & Presentase \\
\hline Bakuto (penjudi) & 26.960 & 5.148 & 32.108 & $(31 \%)$ \\
Tekiya (pedagang keliling) & 21.438 & 2.570 & 24.008 & $(23 \%)$ \\
Gurentai (preman) & 9.861 & 1.639 & 11.500 & $(11 \%)$ \\
Bisnis ilegal di pelabuhan & 3.221 & 0 & 3.221 & $(3 \%)$ \\
Soukaiya & 47 & 2.417 & 2.464 & $(2 \%)$ \\
Pemeras skandal & 41 & 803 & 844 & $(1 \%)$ \\
Gangster prostitusi & 495 & 74 & 569 & $(1 \%)$ \\
Lain-lain & 39 & 29.202 & 29.241 & $(28 \%)$ \\
Total & 62.102 & 41.853 & 103.955 & $(100 \%)$ \\
\hline
\end{tabular}

Sebagian besar latar belakang pekerjaan mereka tidak berbeda dengan organisasiorganisasi kejahatan lainnya. Namun, perlu diketahui hal-hal yang membuat yakuza berbeda. Pertama, ketika organisasi kejahatan lainnya merahasiakan aktivitasnya agar luput dari pengamatan pemerintah, yakuza justru memamerkan diri dengan memasang papan nama di depan gedung kantor mereka yang secara terang-terangan menyebutkan nama kelompok merekamenyerupai kantor bisnis legal. Masingmasing kelompok juga menyematkan pin bergambar simbol yang mengidentifikasikan 
Izumi, Volume 8 No 2, 2019

e-ISSN: 2502-3535 p-ISSN: 2338-249X

Tersedia online di http://ejournal.undip.ac.id/index.php/izumi

kelompok asal pada kerah baju mereka. Kedua, mereka juga dapat dikenali dengan mudah melalui tato yang digambar pada hampir sekujur tubuh dan jari kelingking yang buntung akibat ritual yubitsume atau potong jari. Berbeda dengan Cosa Nostra Amerika yang memiliki aturan tak tertulis agar tidak menonjolkan diri (Raab, 2013, p. 9). Seiring berjalannya waktu, kedua 'tanda pengenal' tersebut semakin jarang ditemukan karena berbagai alasan, sehingga sulit untuk mengidentifikasi apakah seseorang benar merupakan anggota geng atau bukan hanya dari penampilannya. Fakta ini diikuti dengan penurunan jumlah total anggota yakuza yang semakin menurun tiap tahun (P. B. E. Hill, 2006).

Dalam sejarahnya, momen yang paling menjadi kunci kemajuan yakuza adalah fenomena Bubble Economy yang terjadi pada 1985 hingga awal 1990-an, dimana ekonomi Jepang melesat akibat meroketnya nilai real estate dan bursa saham. Fenomena ini juga melahirkan yakuza ekonomi atau keizai yakuza sebagai istilah untuk menyebut para yakuza yang terjun ke bidang ekonomi untuk memanfaatkan momen tersebut (Kaplan, 2011, p. 205). Pada masa inilah bisnis-bisnis unik yakuza meraih kejayaannya, contohnya jiage dan soukaiya. Selain bidang ekonomi, yakuza juga banyak terlibat dalam urusan politik. Kebanyakan yakuza berhaluan ultranasionalis sehingga sangat dekat dengan partai sayap kanan Jepang, membuatnya mudah untuk menginfiltrasi dunia politik. Selain mengatur pemilu, yakuza juga memperluas korupsi ditengah-tengah para politikus serta menyerang media pers yang menyebar berita buruk mengenai kelompok mereka. Seiring berjalannya waktu, politik Jepang berupaya membersihkan diri dari keterlibatan yakuza, sehingga pengaruh yakuza makin terlihat berkurang tiap tahunnya.

\section{2) Kontrol formal}

Dalam membahas kontrol formal, berarti berbicara mengenai badan-badan penegak hukum di Jepang. Otoritas yang cocok menjadi sorotan utama adalah Keisatsu-chou (National Police Agency, atau disingkat NPA) Jepang. Kepolisian Jepang merupakan lembaga formal negara yang memberi dampak sangat signifikan terhadap perkembangan geng-geng yakuza khususnya pada masa lalu.

Meskipun dikenal sebagai bangsa yang disiplin, namun kepolisian Jepang sebenarnya memiliki integritas rendah dibawah badan-badan kepolisian luar negeri lainnya, serta sering terlibat dalam skadalskandal serius terutama pada tahun 90-an (Johnson, 2003). Johnson, dalam jurnalnya mengatakan bahwa ia pernah mengadakan survei untuk menguji integritas polisi-polisi Jepang lewat 12 sajian skenario kasus, dan hasilnya justru menimbulkan pertanyaan. Apabila hasil survei menunjukkan bahwa polisi Jepang adalah aparat berintegritas tinggi, kenyataan justru menunjukkan bahwa mereka banyak terlibat skandal. Diantara skandal-skandal tersebut yang paling membuat malu masyarakat Jepang, diantaranya adalah penemuan bahwa polisipolisi Kanagawa menciptakan manual khusus untuk menutupi skandal (Kanagawa Cover-up, tahun 1991), pengadaan 'cuci otak' terhadap polisi-polisi baru agar mampu menuruti sikap diam atau code of silence agar bisa melakukan pelanggaran dengan aman (Chiba Rape Case, tahun 1995), dan mengonspirasikan jumpa pers palsu (Niigata Kidnapping Case, tahun 2000).

Melihat sejarah rendahnya integritas kepolisian Jepang, ditambah fakta bahwa korupsi telah menjadi hal yang wajar di kalangan polisi, maka tidak heran apabila mereka kemudian memiliki hubungan dekat dengan yakuza. Secara singkat, hubungan 
mereka dapat digambarkan sebagai berikut, polisi bersedia mengatur perizinan bisnisbisnis yakuza seperti pachinko dan toko dewasa, bahkan bersedia mengabaikan pemerasan, apabila yakuza mau membayar (Johnson, 2003). Di luar urusan perizinan, yakuza sendiri juga sering menjadi kekuatan alternatif polisi, dimana campur tangan institusional ini juga tidak mengherankan karena yakuza juga dikenal sebagai 'tukang pukul' bagi partai sayap kanan Jepang di masa lalu. Yakuza sebagai alternatif polisi disini maksudnya menangani kejahatankejahatan non-organisasi.

Hubungan tertutup yang harmonis ini pun tidak mampu bertahan selamanya. Dua perang terbuka antargeng yakuza, yaitu Perang Yama-Ichi pada 1984-89 dan Perang Hachioji pada 1990 telah memperburuk citra yakuza di mata masyarakat Jepang sehingga mendorong kepolisian untuk mencari solusinya (P. Hill, 2003). Dengan menjadikan RICO (The Racketeer Influenced and Corrupt Organizations), undang-undang anti-mafia di Amerika Serikat sebagai model, maka lahirlah undang-undang anti-yakuza yang disebut Boutaihou pada 1991. Fakta bahwa RICO lahir lebih dahulu pada tahun 1970 mengindikasikan kerja lamban pemerintah Jepang dalam rangka menangani kejahatan terorganisasi. Yang jelas, terbitnya Boutaihou menjadi penanda kebangkitan kepolisian Jepang dalam melawan kejahatan terorganisasi, karena secara tegas telah memutus tali persahabatan dengan yakuza.

Boutaihou memberikan dasar hukum bagi polisi Jepang untuk melakukan langkah-langkah preventif dalam menanggulangi aksi-aksi kekerasan oleh member-member yakuza, diantaranya yaitu melakukan kontrol administratif terhadap aktivitas geng, membatasi penggunaan kantor geng, dan mendirikan pusat regional untuk membantu para korban kejahatan dalam memberantas kelompok yakuza terkait (Johnson, 2007). Seiring berjalannya waktu, undang-undang ini terus direvisi agar menjadi lebih baik (P. Hill, 2003). Meskipun tidak seganas RICO, namun Boutaihou terbukti memberi dampak positif yang cukup signifikan. Para godfather yakuza pun mulai merasakan tekanan dalam melakukan aktivitas-aktivitas ilegalnya. Melihat tingginya angka penetapan sementara sejak dirilisnya Boutaihou menunjukkan bahwa undang-undang ini adalah alat yang efektif dalam menangkap anggota-anggota yakuza. Laporan dari kepolisian bahkan menunjukkan penurunan jumlah anggota yakuza sebanyak 70\% pada tahun 2005, sekaligus merupakan pencapaian terbesar kepolisian Jepang dalam menangani kasuskasus bouryokudan. Walaupun begitu, bukan berarti para gangster ini berhenti berkembang-justru mereka mengalami perkembangan yang dinamis. Sebagai contoh, penangkapan pengguna narkoba semakin menurun, namun kasus penipuan semakin meningkat (Special Feature: Progress and Future Prospects Regarding Traffic Safety Measures Preface Special Feature: Progress and Future Prospects Regarding Traffic Safety Measures, 2017) . Selain itu, perluasan pengaruh antar geng masih terjadi, buktinya adalah pecahnya konflik internal dalam Yamaguchi-gumi pada tahun 2016, dimana situasi tersebut tidak bisa diprediksi oleh polisi (Keisatsucho Soshiki Hanzai Taisaku-bu, 2019).

\section{3) Kontrol informal}

Dalam membahas kontrol informal, berarti berbicara mengenai lembaga non-formal yang memberikan peran terhadap kontrol sosial, yang berarti adalah anggota masyarakat. Untuk dapat mendalami peran masyarakat Jepang dalam melakukan 
Izumi, Volume 8 No 2, 2019

e-ISSN: 2502-3535 p-ISSN: 2338-249X

Tersedia online di http://ejournal.undip.ac.id/index.php/izumi

kontrol sosial lebih jauh, maka perlu diketahui budaya masyarakat sebagai dasar berpikir dan bertindak. Secara garis besar, adat-adat orang Jepang bertumpu pada ajaran Konfusianisme (Jiang, Lambert, Liu, \& Saito, 2014). Budaya oyabun-kobun yang diterapkan yakuza juga merupakan produk dari paham ini. Konfusianisme pada intinya mengajarkan bahwa dibandingkan dengan peraturan formal, pengajaran nilai-nilai moral lebih efektif (Levi, 2013). Paham ini mengajarkan ikatan kekeluargaan yang kuat dan karenanya memandang keharmonisan antar kelompok sebagai hal yang paling penting (Bui \& Farrington, 2019). Paham kekeluargaan ini begitu mengakar kuat sehingga melahirkan nilai-nilai solidaritas kelompok, rasa memiliki, dan rasa kesetiaan yang masih banyak ditemukan di tengahtengah masyarakat Jepang, misalnya di lingkungan kantor (Soetanti, 2011). Sehingga, keharmonisan dalam komunitas merupakan jawaban kunci atas sebab rendahnya tingkat kejahatan di Jepang. Namun, prinsip keharmonisan tersebut terlalu kompleks, sehingga memiliki kekurangan.

$$
\text { Dalam rangka mencapai }
$$

keharmonisan hidup, orang Jepang banyak menetapkan aturan tidak tertulis atau etika yang harus ditaati masyarakat. Umumnya, apabila seseorang melanggar etika, dia tidak akan dihukum secara formal, melainkan hanya akan memperoleh cap buruk dari masyarakat. Sebagai masyarakat yang mendambakan keharmonisan, cap buruk tersebut sudah layak dianggap sebagai hukuman, sehingga etika dipandang setara dengan aturan formal. Hal ini lambat laun menyebabkan hubungan antar masyarakat Jepang di era modern menjadi kaku, sehingga rasa empati terhadap 'orang luar' atau soto, cukup dangkal atau renggang. Akibatnya, seseorang menjadi merasa tak acuh terhadap aktivitas yang dilakukan atau diterima oleh orang luar, sehingga apabila terjadi tindak kriminalitas, mereka lebih baik diam dan tidak melapor. Kenyataan ini tentu memberikan peluang bagi yakuza dalam berbagai aspek.

Sistem nilai lain yang memiliki celah adalah giri dan ninjou. Keduanya merupakan karakteristik bangsa Jepang yang merupakan peninggalan dari masa feodal. Sebagai kontrol sosial tipe pra-modern, giri mengharuskan setiap orang untuk bertindak sebagaimana yang seharusnya, sedangkan ninjou adalah nilai yang dapat disejajarkan dengan perasaan atau afeksi manusia (Minami, 1954). Keduanya merupakan budaya kompleks yang sukar dipahami orang luar Jepang karena kaitannya dengan tradisi-tradisi lama. Pada intinya, keduanya adalah tradisi pemberian hadiah kepada satu sama lain sebagai suatu kewajiban. Terkadang, orang Jepang sendiri bahkan tidak tahu apakah yang diterimanya merupakan hadiah atau suap, yang jelas secara moral ia merasa wajib membalas si pemberi hadiah (Kaplan, 2011, p. 177). Maka dari itu, sulit menyatakan apakah seorang pejabat terlibat dalam kasus penyuapan dikarenakan tidak ada cara yang dapat membuktikannya secara efektif. Untuk memperparah keadaan, kegiatan suapmenyuap merupakan kunci bagi kelompok mafia manapun untuk mendapatkan aksesakses khusus, tak terkecuali yakuza. Fakta ini, ditambah dengan korupnya kepolisian Jepang, menyebabkan bisnis yakuza tumbuh subur di Jepang. Kelompok-kelompok yakuza ini tentu tidak memberikan suap atau hadiah secara langsung, melainkan melalui perusahaan-perusahaan rekanan mereka.

Faktor yang paling mungkin menjembatani hubungan antara yakuza dengan masyarakat secara langsung adalah budaya malu. Hal ini sangat tercermin dalam perusahaan-perusahaan Jepang yang selalu mengutamakan konsumen demi menjaga 
Izumi, Volume 8 No 2, 2019

e-ISSN: 2502-3535 p-ISSN: 2338-249X

Tersedia online di http://ejournal.undip.ac.id/index.php/izumi

reputasi dirinya. Akibatnya, mereka jadi lemah terhadap pemerasan dan intimidasi fisik yang berpotensi mengancam reputasinya. Faktor inilah yang menyebabkan bisnis sarakin yakuza tumbuh subur. Sarakin dapat diartikan sebagai lintah darat. Biasanya, pihak yang menjalankan bisnis sarakin bukanlah dari kelompok yakuza itu sendiri, melainkan pihak mandiri yang suka menyewa jasa yakuza dalam menagih utang kliennya. Selain lintah darat, pemerasan juga cukup populer di kalangan yakuza. Banyak perusahaan atau institusi pendidikan yang memiliki skandal menjadi sasaran pemerasan. Mereka takut bila keburukan perusahaan bocor ke publik, reputasi akan terancam, sehingga mereka bersedia membayar uang tutup mulut kepada si pemeras. Mungkin spesialis dalam pemerasan perusahaan semacam itu adalah soukaiya, sekaligus merupakan bisnis yang unik sepanjang sejarah dunia hitam. Pada dasarnya, para soukaiya tidak berasal dari kelompok yakuza, namun mereka banyak didukung oleh yakuza-hubungan yang hampir mirip antara sarakin dengan yakuza. Pekerjaan mereka adalah memeras perusahaan-perusahaan yang memiliki skandal. Apabila perusahaan tidak bersedia memberi uang tutup mulut, maka para soukaiya akan turun ke dalam rapat umum pemegang saham perusahaan yang bersangkutan untuk membeberkan aib perusahaan, mencaci manajer perusahaan, atau menyebar fitnah perusahaan (Leheny, 2003).

\section{SIMPULAN}

Dari penemuan-penemuan diatas dapat disimpulkan bahwa yakuza dapat berkembang di tengah masyarakat Jepang adalah salah satunya akibat kontrol sosial yang kurang efektif dan penanganan yang lamban. Dikatakan demikian karena melihat integrasi dan komitmen buruk kepolisian Jepang yang memberi peluang untuk suapmenyuap dan korupsi, serta masyarakat yang lemah terhadap ancaman dan intimidasi. Rapuhya hubungan sosial di Jepang juga menjadi salah satu penyebab dasarnya. Lambatnya kepolisian Jepang dalam menciptakan instrumen anti-yakuza memberikan ruang bagi yakuza untuk membangun posisi yang kuat di masyarakat, membuatnya semakin sulit dibasmi pada masa mendatang. Namun, berkat disahkannya Boutaihou pada 1991, para yakuza yang tadinya tak tersentuh hukum kemudian menjadi tertekan. Terbukti jumlah anggota total yakuza yang lambat laun semakin berkurang. Walaupun begitu, sama halnya dengan usaha Amerika Serikat dalam melawan mafia, nampaknya dibutuhkan waktu yang sangat panjang bagi kepolisian Jepang untuk dapat mengusir kejahatan terorganisasi di negaranya.

\section{REFERENSI}

Albanese, J. S. (2016). Kejahatan Terorganisasi (Organized Crime) Akar dan Perkembangannya (6th ed.). Jakarta: Prenadamedia Group.

Braithwaite, J. (1989). Crime, Shame, and Reintegration. Cambridge: Cambridge University Press.

Bui, L., \& Farrington, D. P. (2019). Crime in Japan: A psychological perspective. Palgrave Macmillan. Retrieved from https://b-ok.cc/book/5243170/684a7b

Hill, P. (2003). Heisei Yakuza: Burst Bubble and Botaiho. Social Science Japan Journal, 6(1), 1-18. Retrieved from https://academic.oup.com/ssjj/article/6/ $1 / 1 / 1665971$ 
Izumi, Volume 8 No 2, 2019

e-ISSN: 2502-3535 p-ISSN: 2338-249X

Tersedia online di http://ejournal.undip.ac.id/index.php/izumi

Hill, P. B. E. (2006). The Japanese Mafia: Yakuza, Law, and the State. Oxford University Press.

Jiang, S., Lambert, E. G., Liu, J., \& Saito, T. (2014). Formal and informal control views in China, Japan, and the U.S. Journal of Criminal Justice, 42, 36-44. Retrieved from https://www.jstor.org/stable/10.1086/59 2808\%0AJSTOR

Johnson, D. T. (2003). Above the Law? Police Integrity in Japan. Social Science Japan Journa, 6(1), 19-37. Retrieved from https://www.jstor.org/stable/30209411

Johnson, D. T. (2007). Crime and Punishment in Contemporary Japan, 36(1), 371-423.

Kaplan, D. E. (2011). Yakuza: Sejarah Dunia Hitam Jepang. Jakarta: Komunitas Bambu.

Leheny, D. (2003). The Society for Japanese Studies. The Journal of Japanese Studies, 29(2), 460-464. Retrieved from https://www.jstor.org/stable/25064432

Levi, N. (2013). The Impact of Confucianism in South Korea and Japan, (26), 7-16. Retrieved from yadda.icm.edu.pl>12-Levi-ver02-

poprawione

Liu, J., \& Miyazawa, S. (Eds.). (2018). Crime, and Criminal Justice in Contemporary Japan. Springer. https://doi.org/10.1007/978-3-31969359-0_3

Minami, H. (1954). Human Relations In The Japanese Society. The Annals of the Hitotsubashi Academy, 4(2), 148-162.
Raab, S. (2013). Lima Keluarga Besar Mafia (Five Families) (1st ed.). Jakarta: Kaki Langit Kencana.

Soetanti, D. (2011). Rasa Solidaritas Kelompok, Rasa Memiliki, dan Rasa Kesetiaan Sebagai Nilai-Nilai Tradisi Jepang Dalam Sistem Manajemen Perusahaan di Jepang. Majalah Ilmiah Unikom, 6(2), 213-220.

Special Feature: Progress and Future Prospects Regarding Traffic Safety Measures Preface Special Feature: Progress and Future Prospects Regarding Traffic Safety Measures. (2017). Retrieved from https://www.npa.go.jp/hakusyo/h27/en glish/White_Paper_2015.pdf

Wibawarta, B. (2006). Bushido dalam Masyarakat Jepang Modern. Wacana, $8(1)$, 54-66. Retrieved from https://www.researchgate.net/publicatio n/279275033_Bushido_dalam_Masyar akat_Jepang_Modern 